\title{
Conhecimento de enfermeiros da Estratégia Saúde da Família sobre resíduos dos serviços de saúde
}

\author{
Knowledge of nurses of the Family Health Strategy on health services waste
}

Conocimiento de enfermeros de la Estrategia Salud de la Familia sobre los residuos de servicios de salud

\section{Maíra Azevedo dos Santos', Anderson de Oliveira Souza"}

' Faculdade de Quatro Marcos. Curso de Enfermagem. São José dos Quatro Marcos-MT, Brasil.

"Universidade Federal do Amazonas - Campus de Coari, Departamento de Biotecnologia. Coari-AM, Brasil.

\author{
Submissão: 07-12-2010 Aprovação: 08-10-2012
}

\section{RESUMO}

O estudo realizado aborda a problemática envolvendo os resíduos sólidos de serviços de saúde e a atitude do enfermeiro perante os aspectos relacionados ao gerenciamento e a conscientização ambiental. Participaram da pesquisa dez profissionais atuantes na Estratégia de Saúde da Família, dos municípios de Araputanga, Mirassol D'oeste e São José dos Quatro Marcos. Os dados foram obtidos através da aplicação de questionários, posteriormente analisados através do software Origin ${ }^{\circledR}$. Observou-se o nível de conhecimento em relação à legislação vigente, etapas de manejo realizadas em âmbito municipal e capacitação da equipe e, ainda, a respeito da habilidade dos profissionais em diagnosticar situações de risco ocupacional e para a saúde pública. Apesar da existência de um significativo conhecimento sobre o tema, ainda há necessidade de trabalhos de conscientização e desenvolvimento de práticas adequadas de gerenciamento de Resíduos de Serviços de Saúde.

Descritores: Enfermagem em Saúde Pública; Resíduos de Serviços de Saúde; Educação em Saúde.

\begin{abstract}
The study addresses the problem involving the solid waste from health service and the nurses attitude towards aspects related to the management and environmental awareness. Participants were ten professionals working in the Family Health Strategy, from the municipalities of Araputanga, Mirassol D'west and São José dos Quatro Marcos. Data were collected through questionnaires, and analyzed using the software Origin ${ }^{\circledast}$. It was observed the level of knowledge regarding the current law, management steps taken at the municipal and staff training, and also about the ability of the professionals to diagnose situations and occupational risk to public health. Despite the existence of a significant knowledge on the subject, there is still need to work on awareness and development of appropriate management practices on the health services waste.
\end{abstract}

Key words: Public Health Nursing; Wastes of Health Services; Health Education.

\section{RESUMEN}

El estudio aborda los problemas relacionados con los residuos sólidos del servicio de salud y la actitud de los enfermeros hacia los aspectos relacionados con la gestión y la concientización ambiental. Participaran del estudio diez profesionales que trabajan en la Estrategia de Salud Familiar, en los municipios de Araputanga, Mirassol D’Oeste y São José dos Quatro Marcos. Los datos se obtuvieron mediante la aplicación de cuestionarios, posteriormente analizados a través del software Origin ${ }^{\circledast}$. Se observó el nivel de conocimientos sobre la legislación vigente, las medidas de gestión adoptadas en ámbito municipal y también la capacidad de los profesionales para diagnosticar situaciones de riesgos ocupacionales y para la salud pública. A pesar de la existencia de un conocimiento significativo sobre el tema, todavía hay que trabajar en la sensibilización y en el desarrollo de prácticas apropiadas de gestión de los residuos de los servicios de salud

Palabras clave: Enfermería de Salud Pública; Servicios de Residuos de Salud; Educación para la Salud. 


\section{INTRODUÇÃO}

O ser humano busca diariamente a superação de limites e investe constantemente em pesquisas e aprimoramentos que tem por finalidade a facilitação e a comodidade do dia-a-dia. Em pró dos avanços tecnológicos, muito foi extraído do meio ambiente, e nele arremessado inconsequentemente o que já "não serve". Surgem então diversos problemas ambientais, como a destruição de recursos naturais, aumento da poluição que se agrava constantemente em decorrência do crescimento populacional, o que acaba por influenciar a qualidade de vida da humanidade, sendo uma ameaça aos suportes de vida ${ }^{(1-2)}$.

A Associação Brasileira de Normas Técnicas (ABNT) conceitua Resíduos Sólidos como "resíduos nos estados sólido e semissólido, que resultam de atividades da comunidade de origem: industrial, doméstica, comercial, agrícola, de serviços e de varrição"(3).

No Brasil, são gerados diariamente cerca de 230 mil toneladas de resíduos, dos quais uma quantia considerável não recebe o devido tratamento, terminando em lixões a céu aberto e resultando em prejuízos a saúde pública decorrentes da poluição do solo, do ar e das águas. E ainda, de forma indireta servindo de meio de cultura e proliferação de agentes infecciosos nocivos ao ser humano e aos demais seres vivos, que em consequência do contato com a contaminação tornam-se também vetores de patologias ${ }^{(1,4)}$.

"Os Resíduos de Serviços de Saúde (RSS) têm despertado especial atenção das autoridades e da população em geral sobre a importância e o significado desses, como risco potencial para a saúde humana e ambiental". Podem ser conceituados como "todo o lixo gerado em qualquer serviço prestador de assistência médica, sanitária ou estabelecimentos congêneres ${ }^{(5-6)}$.

A preocupação com o gerenciamento dos RSS pode ser considerada recente no contexto hospitalar e serviços afins. Somente na última década, após a publicação da RDC n 306/04 da Agência Nacional de Vigilância Sanitária (ANVISA); e da Resolução no 358/05 do Conselho Nacional do Meio Ambiente (CONAMA), este tema passou a ganhar espaço e ainda se encontra em fase de amadurecimento no país. Ambas as resoluções foram coadunadas entre si para melhor atender as necessidades dos profissionais envolvidos no manejo dos RSS ${ }^{(7-8)}$.

"O gerenciamento dos resíduos de saúde tem como objetivo minimizar a produção dos mesmos e proporcionar um encaminhamento seguro, visando à proteção dos trabalhadores e a preservação do ambiente" ${ }^{\prime \prime(7)}$.

Todo estabelecimento que se enquadre como gerador de RSS deve elaborar um plano de gerenciamento, baseando-se nas características dos resíduos a serem descartados, e nas normas locais referentes à coleta, transporte e disposição final. De acordo com a RDC no 306/04, o Plano de Gerenciamento de Resíduos de Serviços de Saúde (PGRSS) pode ser definido como "o documento que aponta e descrevem as ações relativas ao manejo dos resíduos sólidos, observadas suas características e riscos, no âmbito dos estabelecimentos"(9).

O PGRSS deve orientar os funcionários da instituição quanto às rotinas a serem adotadas nas várias etapas de manejo dos resíduos e também nas situações de emergência e acidentes. Definir o fluxo de coleta interna e externa dos RSS, o encaminhamento para o processo de esterilização ou trituração e organização do número de coletas necessárias para cada unidade $^{(10)}$.

Quanto ao aspecto de gerenciamento, enfatizamos que "cabe à enfermagem desenvolver atividades para a manutenção e promoção de saúde, bem como para a prevenção de doenças, sendo de sua responsabilidade o diagnóstico e a intervenção de enfermagem" ${ }^{\prime \prime 11)}$. A partir deste preceito, entende-se que promover a saúde do meio ambiente também é um dever do enfermeiro, a fim de evitar agravos inerentes ao ser humano.

A estratégia de promoção em saúde visa identificar fatores que comprometam a saúde da população, que por sua vez variam de acordo com diversidade e necessidades do ambiente em que vivem. Assim, torna-se possível estabelecer metas e prioridades adequadas a cada território, a fim de alcance da melhoria nos níveis da qualidade de vida. Dentre seus princípios norteadores destacam-se "favorecer a preservação do meio ambiente e a promoção de ambientes mais seguros e saudáveis" e "prevenir fatores determinantes e/ou condicionantes de doenças e agravos à saúde"(12).

A Estratégia de Saúde da Família (ESF) é uma iniciativa governamental que objetiva reorganizar a prática assistencial, substituindo o modelo tradicional baseado na cura da doença e na hospitalização, por uma abordagem mais direcionada ao contexto familiar, sendo a promoção da saúde um dos focos primordiais da abordagem. Dentre os objetivos específicos, ressalta-se a intervenção da equipe nos fatores de risco, os quais a população está exposta ${ }^{(13)}$.

Tendo em vista que os prejuízos provocados ao meio ambiente refletem diretamente na qualidade de vida dos seres humanos, comprometendo a saúde e o bem-estar da população, o estudo objetivou analisar o conhecimento das enfermeiras atuantes na ESF, dos municípios de Araputanga, Mirassol D'Oeste e São José dos Quatro Marcos, referente à problemática do manejo incorreto dos RSS, a necessidade de conhecer adequadamente as normas pertinentes, e ainda quanto à capacitação dos profissionais envolvidos no processo de gerenciamento.

\section{METODOLOGIA}

O estudo teve início com a pesquisa bibliográfica sobre os resíduos sólidos, em especial os gerados em serviços de saúde, sua implicação na sociedade e o papel da enfermagem no gerenciamento adequado para a proteção e manutenção da saúde humana e ambiental. A maioria das informações utilizadas foi obtida através de artigos científicos, que constituem os estudos mais recentes sobre a problemática em questão. Outra base de suma importância foi a RDC $n^{\circ}$ 306, de 7 de dezembro de 2004, que regulamenta o gerenciamento de RSS e oferece as informações necessárias a elaboração do PGRSS.

Realizou-se a aplicação de questionários quantitativos (previamente aprovado pelo Comitê de Ética e Pesquisa da Faculdade de Quatro Marcos sob Protocolo no 1.113/2010), respeitando os princípios éticos exigidos, sendo a participação no 
estudo facultativa. O questionário foi composto de cinco perguntas objetivas direcionadas aos enfermeiros atuantes na ESF dos municípios de Araputanga, Mirassol D'oeste e São José dos Quatro Marcos, localizados a oeste do Estado de Mato Grosso. Optou-se pelas referidas cidades devido à proximidade entre as mesmas e índice populacional, que varia entre 15.000 a 25.000 habitantes.

A população pesquisada foi composta exclusivamente por profissionais do sexo feminino, selecionadas por atuarem na ESF dos municípios da região em foco. No município de Araputanga existem duas Unidades de Saúde da Família (USF) e um Centro de Saúde; aceitaram responder o questionário proposto duas das três enfermeiras, uma atuante no centro e outra da USF. Em Mirassol D'oeste totalizam-se três USF e um Centro de Saúde, e participaram da pesquisa todas as enfermeiras das unidades e uma do centro. Na cidade de São José dos Quatro Marcos, que possui quatro USF, foram entrevistadas todas as enfermeiras. No total, participaram da pesquisa dez profissionais.

O questionário avaliou, nas duas perguntas iniciais, o conhecimento do enfermeiro em relação à RDC n 306/04, bem como a proposta que o mesmo faz para o acondicionamento dos resíduos gerados em sua unidade. A terceira e quarta pergunta investiga o conhecimento do profissional sobre as etapas de manejo e disposição final. Na quinta e última pergunta, questionou-se a capacitação da equipe em relação aos RSS. Em relação às respostas, optou-se por limitá-las entre as alternativas: Sim, não ou desconhece, objetivando facilitar a construção dos gráficos.

Apesar de conhecer alguns problemas de gerenciamento de resíduos sólidos existentes na região pesquisada, o estudo mantém o seu foco direcionado à avaliação da postura do enfermeiro em relação aos "lixos" gerados por sua unidade. Com base nas respostas obtidas para cada questão, foram construídos gráficos que facilitam a visualização dos resultados e permitem analisar o posicionamento predominante entre as profissionais frente às diferentes questões sobre o gerenciamento dos RSS.

Por tratar-se de um questionário quantitativo, os dados foram analisados através de softwares estatísticos, os quais propiciam verificações dos dados a serem analisados. Mediante a diversidade tecnológica, utilizamos o Origin ${ }^{\circledR}$ por apresentar ferramentas mais completas e, com isso, maior garantia dos resultados a serem analisados. Ainda, tal recurso apresenta um nível fácil de manipulação, ou seja, garantia de um excelente trabalho estatístico mesmo para aqueles que não tiveram contato prévio com o software.

\section{RESULTADOS}

A pesquisa foi realizada com bacharéis em Enfermagem, exclusivamente do sexo feminino, integrantes do quadro de profissionais da Atenção Básica dos municípios referidos. A faixa etária variou entre 22 e 36 anos. Observou-se também que 7 das entrevistadas atuam há menos de 3 anos na profissão, e apenas 3 atuam há mais de 5 anos.

O primeiro questionamento investiga o conhecimento do enfermeiro em relação à resolução mencionada, através da aplicação da seguinte pergunta: "Você tem pleno conhecimento sobre a RDC no 306, de 7 de dezembro de 2004, que regulamenta o gerenciamento dos RSS?" Ressalte-se que o Regulamento Técnico para o Gerenciamento de RSS deve ser aplicado em todo o território nacional, na rede pública e privada, e o não cumprimento configura infração sanitária sujeita as penalidades previstas na Lei $\mathrm{n}^{\circ}$. 6.437, de 20 de agosto de $1977^{(9)}$.

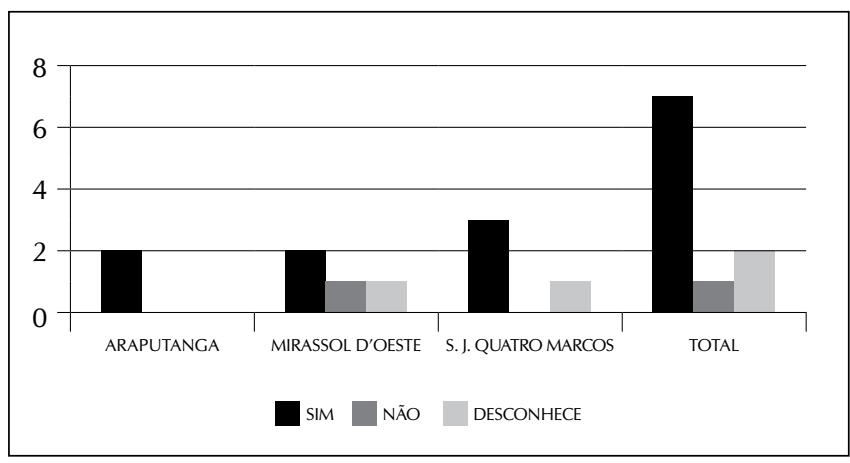

Gráfico 1 - Conhecimento das profissionais entrevistadas sobre a RDC n³ 306/2004.

Na cidade de Araputanga, as duas profissionais entrevistadas, afirmaram ter pleno conhecimento sobre a legislação vigente, tendo ambas optado pela alternativa "sim". Em Mirassol D'Oeste, das quatro enfermeiras entrevistadas, duas escolheram a opção "sim"; uma profissional optou por "não", alternativa que refere o conhecimento parcial sobre a regulamentação; e uma "desconhece", alegando não saber do que se trata a RDC n. 306/04. Em São José dos Quatro Marcos, também foram questionadas quatro enfermeiras, sendo que três escolheram a alternativa "sim" e uma optou por "desconhece". No total, houve a prevalência da opção "sim", escoIhida por sete das dez enfermeiras entrevistadas. Apenas duas profissionais afirmaram desconhecer a legislação em vigor; e uma, ter um conhecimento apenas parcial sobre o tema.

A segunda pergunta do questionário propõe ao profissional entrevistado que faça um diagnóstico da situação atual dos RSS em sua unidade. As respostas obtidas estão diretamente ligadas ao conhecimento prévio do enfermeiro em relação à RDC n 306/04(9), legislação, que é indispensável à correta avaliação situacional. A pergunta realizada foi: "O acondicionamento dos resíduos gerados em sua unidade está de acordo com o que preconiza esta Resolução?"

As duas profissionais entrevistadas em Araputanga afirmaram que os RSS gerados estão dispostos de maneira adequada, ambas optando pela alternativa "sim" do questionário. Das quatro entrevistadas em Mirassol D'Oeste, duas preferiram a alternativa "sim"; uma "não"; e uma "desconhece". Em São José dos Quatro Marcos, apenas uma das enfermeiras entrevistadas avalia como correto o acondicionamento dos resíduos em sua unidade, respondendo "sim" a questão, tendo as outras três, escolhido a alternativa "não" da pergunta proposta. 


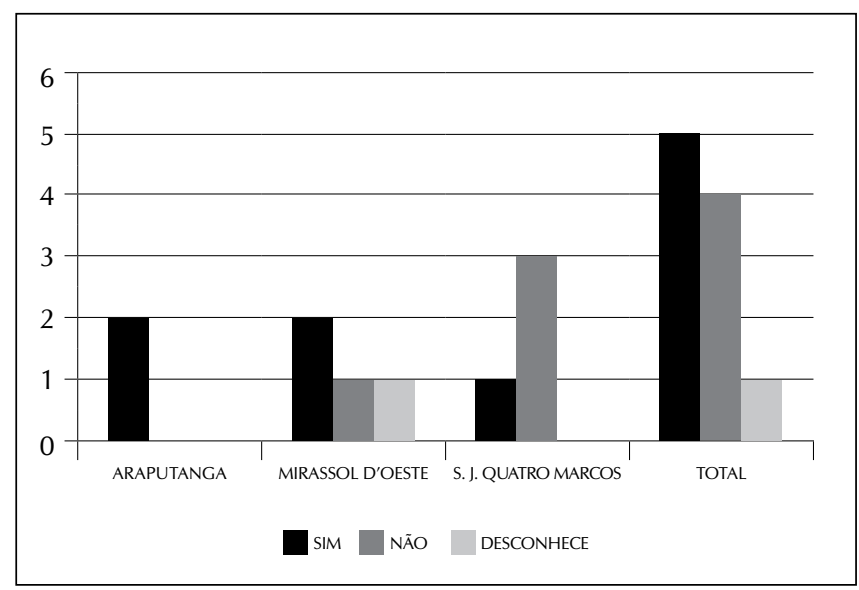

Gráfico 2 - Conhecimento das profissionais entrevistadas sobre o respeito ao que preconiza a RDC n 306/2004 para o acondicionamento dos resíduos gerados na ESF.

Das dez enfermeiras entrevistadas, cinco declararam como correta a forma de acondicionamento de resíduos em sua unidade, quatro afirmaram a existência de um processo inadequado, e uma alegou desconhecer a existência ou não de irregularidades. A não padronização do acondicionamento dos RSS foi constatada com tal questionamento o que pode ocasionar graves danos ambientais.

A terceira pergunta do questionário foi: "Você conhece passo a passo as etapas de manejo e disposição final dos resíduos gerados pela sua unidade?" O principal objetivo da questão foi avaliar o conhecimento do enfermeiro em relação às etapas de gerenciamento dos RSS, não somente dentro de sua unidade, mas em todas as fases do processo que envolve o manejo. Segundo a RDC n 306/04 "os serviços de saúde são os responsáveis pelo correto gerenciamento de todos os RSS por eles gerados, atendendo as normas e exigências legais, desde o momento de sua geração até a sua destinação final"(9).

Na cidade de Araputanga, uma enfermeira optou por "não" e a outra "desconhece". Em Mirassol D'Oeste, apenas uma das quatro profissionais entrevistadas escolheu a alternativa "sim"; das demais enfermeiras, uma respondeu "não" e duas "desconhece". Em relação a São José dos Quatro Marcos, as respostas obtidas foram idênticas as de Mirassol D'Oeste, visto que se equivale o número de entrevistadas.

De maneira geral, é nítida a predominância das enfermeiras que não conhecem as etapas de manejo dos resíduos, sendo um total de oito, entre as dez entrevistadas. Desta forma, um treinamento envolvendo a temática poderia sanar tal oscilação entre as respostas.

O quarto questionamento abordado refere-se à avaliação que o enfermeiro fez sobre o gerenciamento dos resíduos de sua unidade, através da seguinte questão: "Existe irregularidades durante esse processo?".

Para a identificação da existência de um manejo inapropriado é necessário que a profissional conheça o gerenciamento realizado, ou mesmo esteja a par das dificuldades encontradas em seu município em relação à coleta e disposição de resíduos.

As entrevistadas em Araputanga responderam "desconhece"

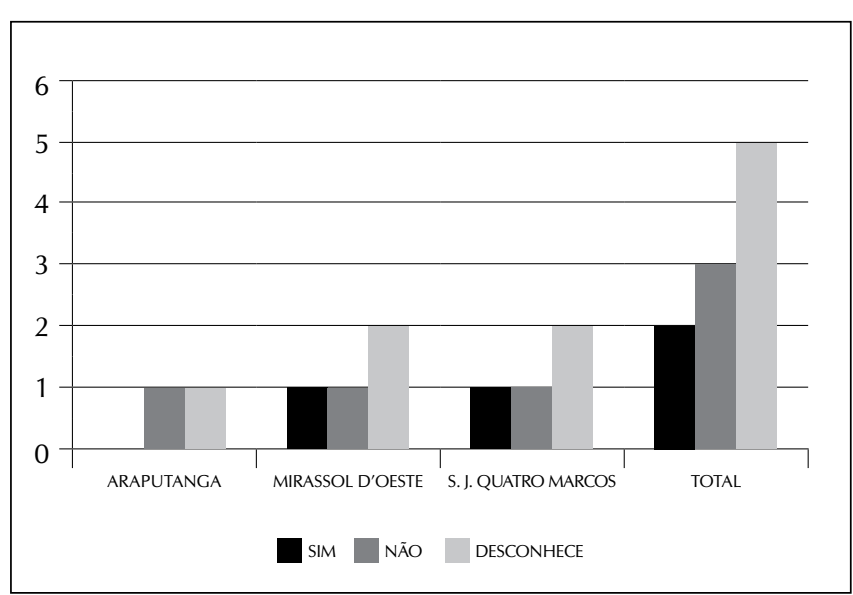

Gráfico 3 - Conhecimento das profissionais entrevistadas sobre as etapas de manejo e disposição final dos resíduos gerados pela ESF.

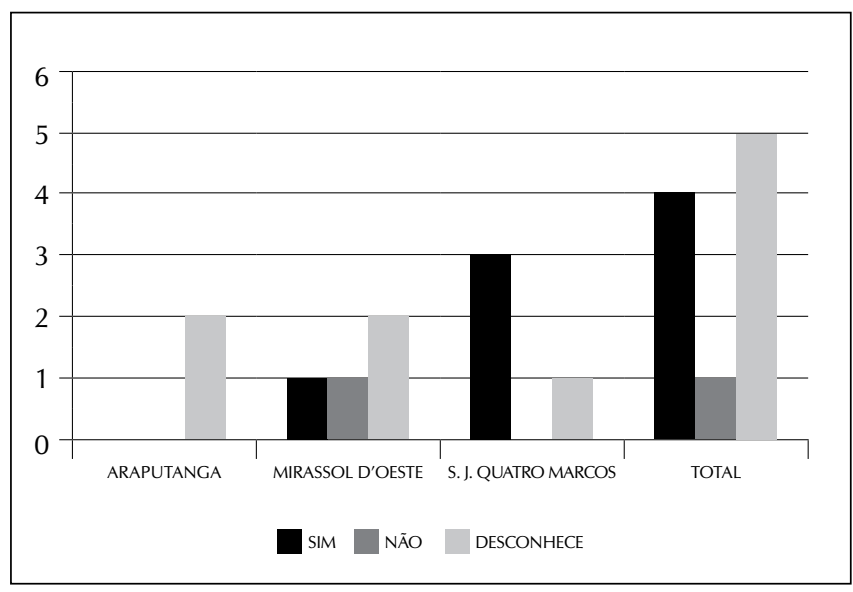

Gráfico 4 - Conhecimento das profissionais entrevistadas sobre a existência de manejo inapropriado dos resíduos gerados pela ESF.

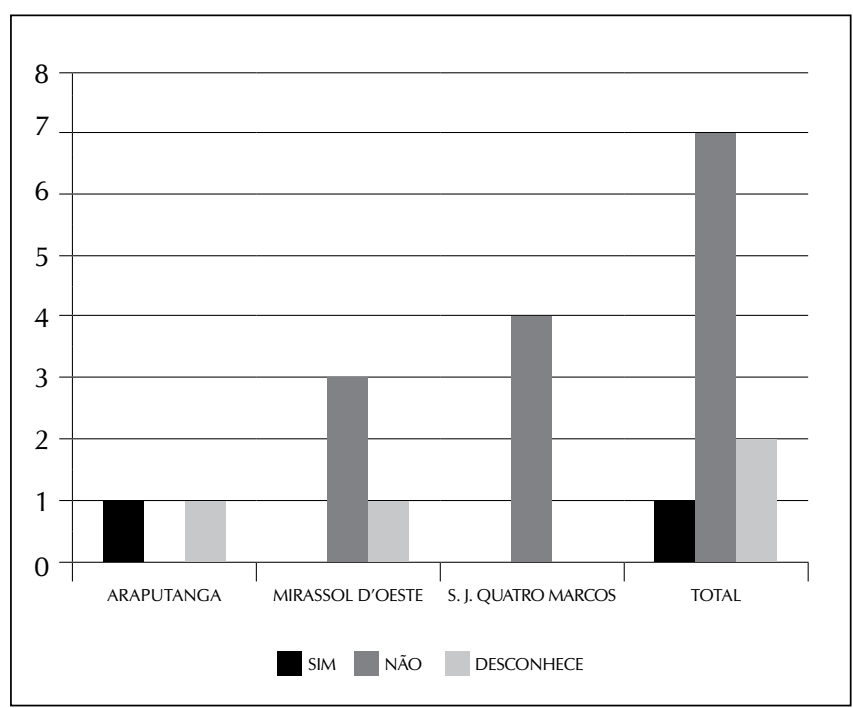

Gráfico 5 - Conhecimento das profissionais entrevistadas sobre iniciativas para qualificar a equipe envolvida no manejo de resíduos. 
à referida pergunta. Em Mirassol D'Oeste, uma enfermeira afirmou a existência de irregularidades optando pela alternativa "sim"; duas "desconhece"; e apenas uma referiu à inexistência de falhas no processo. Quanto a São José dos Quatro Marcos, predominou o número de profissionais que referem o manejo como inadequado, sendo que três entre as quatro entrevistadas optaram pela alternativa "sim" e apenas uma por "desconhece".

Entre as dez entrevistadas, cinco disseram desconhecer a existência ou não de falhas nas etapas de manejo; quatro apontaram a existência de irregularidades; e apenas uma disse não existir tal problemática.

Na quinta e última questão abordou-se a iniciativa, seja por parte do município como também do enfermeiro da unidade, de preparar a equipe envolvida no manejo de resíduos. De acordo com a RDC no 306/04, é de competência dos serviços geradores de RSS "prover a capacitação e o treinamento inicial e de forma continuada para o pessoal envolvido no gerenciamento de resíduos"(9). O questionamento foi: "Sua equipe já passou por algum minicurso de capacitação sobre gerenciamento de Resíduos dos Serviços de Saúde?"

Em Araputanga, uma enfermeira escolheu a alternativa "sim", que indica uma preparação específica da equipe; e outra "desconhece" a existência de tal capacitação. Em Mirassol D'Oeste, três entrevistadas assinalaram "não", que refere a inexistência de qualquer preparação dos recursos humanos envolvidos; e uma "desconhece". Em São José dos Quatro Marcos, todas as enfermeiras entrevistadas optaram pela alternativa "não".

Nos índices gerais, um total de sete profissionais negaram a capacitação da equipe em relação ao gerenciamento, duas desconhecem a existência ou não deste tipo de treinamento, e apenas uma referiu a capacitação equipe.

\section{DISCUSSÃO}

Segundo as diretrizes preconizadas pela Política Nacional de Atenção Básica (2006), para a implantação das equipes de Saúde da Família, faz-se necessária a "existência de equipe multiprofissional responsável por no máximo 4.000 habitantes, sendo a média recomendada de 3.000 habitantes, com jornada de trabalho de 40 horas semanais para todos os seus integrantes e composta por no mínimo, médico, enfermeiro, auxiliar de enfermagem ou técnico de enfermagem e Agentes Comunitários de Saúde" ${ }^{\prime(14)}$.

De acordo com os resultados da última pesquisa do Instituto Brasileiro de Geografia e Estatística (IBGE), realizada no ano de 2010, a população do total do município de Araputanga é de 15.342 pessoas; em Mirassol D'Oeste, 25.299; e São José dos Quatro Marcos, 18.998 ${ }^{(15)}$. Nestes municípios foram encontrados um total de nove USFs e dois centros de saúde, apresentando grande fluxo de pacientes.

Observa-se que nas cidades mencionadas apenas uma equipe atua em cada unidade, e até mesmo nos centros de saúde só foi possível encontrar uma enfermeira em cada estabelecimento, o que torna o número de profissionais inferior ao recomendado pela Política Nacional de Atenção Básica. Das três enfermeiras encontradas na cidade de Araputanga, apenas duas se disponibilizaram a responder o questionário. Nos demais municípios todas as profissionais localizadas na data da pesquisa aceitaram colaborar com o estudo.

Ao avaliar os resultados obtidos em relação à questão 1 , que investiga o conhecimento sobre a legislação vigente, observou-se que Araputanga obteve o melhor aproveitamento, já que todas as profissionais afirmaram ter um bom conhecimento sobre a RDC n. 306/04; seguido de São José dos Quatro Marcos, onde três das quatro entrevistadas disseram conhecer plenamente a legislação; em Mirassol D'Oeste, duas das quatro entrevistadas alegaram saber ao certo do que se trata esta regulamentação. Entretanto, é importante considerar que a quantidade de enfermeiras que participaram do estudo na cidade de Araputanga é inferior em relação aos demais municípios.

O índice total alcançado é satisfatório, visto que a maioria das entrevistadas reconhece a existência da legislação.

Conhecer as normas vigentes torna o enfermeiro apto a avaliar as condições de trabalho em que exerce suas funções, podendo assim treinar sua equipe e alertá-los sobre a necessidade da disposição correta dos RSS. "As atividades realizadas nos serviços de saúde produzem uma quantidade considerável de resíduos. Portanto os profissionais que atuam nestes estabelecimentos tornam-se diretamente responsáveis pelos mesmos"(16).

"O destino adequado dos resíduos, através de ações básicas, protege o meio ambiente e a sociedade". Quando dispostos inadequadamente provocam a contaminação do solo, do ar e das águas, além de contribuir para proliferação de doenças, tornando-se assim um problema de saúde pública ${ }^{(16)}$.

$\mathrm{Na}$ questão 2, que refere-se a avaliação do acondicionamento realizado na unidade, foi possível constatar que em Araputanga o acondicionamento é satisfatório, visto que todas as entrevistadas o definiram como adequado; em Mirassol D'Oeste, das quatro unidades em questão, a metade foi bem avaliada pela enfermeira responsável, em relação ao acondicionamento de resíduos; contudo em São José dos Quatro Marcos, três das quatro entrevistadas apontaram como irregular a disposição de resíduos dentro de sua unidade.

Após comparar os gráficos 1 e 2, construídos com base nas respostas obtidas, nas cidades mencionadas, observou-se a semelhança nos índices alcançados por Araputanga e Mirassol D'Oeste, já que em ambas as cidades as respostas dadas a questão 1 foram idênticas para questão 2. Em São José dos Quatro Marcos os índices se diferem, resultando em uma alteração significativa entre os gráficos comparados, provocada pela prevalência na escolha da alternativa "não". Apesar de duas profissionais desconhecerem a legislação, nove entrevistadas conseguiram diagnosticar a atual situação de acondicionamento dos resíduos. Resultado que pode ser considerado satisfatório, visto que prevalece o número de enfermeiras que tem um posicionamento frente à situação de sua unidade.

A etapa de acondicionamento dos resíduos é parte indispensável em um plano de manejo de RSS. Diretamente ligada à segregação, possibilita a prevenção de contato com os seres vivos e o meio ambiente facilitando uma destinação adequada. Segregar e acondicionar de forma incorreta provoca a contaminação de produtos poderiam ser reciclados e aumenta-se o volume de resíduos contaminados desnecessariamente ${ }^{(17)}$. 
Para a questão 3, referente ao conhecimento sobre as etapas de manejo e disposição final dos RSS gerados nas unidades, faz-se importante avaliar o significado das alternativas propostas. Ao optar pela alternativa "sim", entendeu-se que a profissional em questão tem pleno conhecimento sobre o manejo dos resíduos desde a geração até a disposição final. As opções "não" e "desconhece" foram considerados equivalentes, visto que ambas afirmam o desconhecimento em relação às fases de gerenciamento.

Quando considerado o desempenho individual de cada município, observou-se que em Araputanga nenhuma enfermeira afirmou conhecer as etapas de gerenciamento em todas as fases. Em Mirassol D'Oeste e São José dos Quatro Marcos apenas uma profissional em cada município referiu estar a par do processo que envolve desde a geração até a disposição final.

O resultado obtido é insatisfatório, pois predomina o número de entrevistadas que não conhecem precisamente as etapas pelas quais são submetidos os resíduos de sua unidade, sendo oito entre as 10 entrevistadas, fato esse preocupante, pois, tal questionamento torna-se primordial no direcionamento final dos RSS.

Tendo em vista que os enfermeiros tem como parte de suas responsabilidades promoverem a saúde da população, faz-se necessário ressaltar novamente a importância de sua preocupação com o gerenciamento de resíduos. Sua formação Ihe torna apto a fazer intervenções e coordenar o PGRSS, bem como identificar situações problemáticas e propor medidas alternativas $^{(18)}$.

Sobre a questão 4, que investiga o conhecimento sobre a existência ou não de irregularidades no manejo de RSS, foi possível constatar que, no município de Araputanga, por não conhecerem a fundo como funciona o PGRSS adotado, as enfermeiras preferiram não manifestar uma avaliação sobre o mesmo. Em Mirassol D'Oeste, uma enfermeira nega irregularidades, uma disse existir e as demais se mantiveram neutras. Na cidade de São José dos Quatro Marcos, apesar da maioria das enfermeiras desconhecerem como funciona o processo, apenas uma preferiu não avaliá-lo, sendo que as demais afirmaram que o mesmo é irregular.

Apesar do questionamento anterior, oito das entrevistadas afirmarem desconhecer o referido processo, no presente, cinco assumiram um posicionamento, e as demais desconhecem. Quatro das profissionais apontam como irregular, sendo três destas, atuantes no município de São José dos Quatro Marcos. Apenas uma entrevistada considera os procedimentos adequados no município de Mirassol D'Oeste.

Os referidos dados regionais coadunam com a Pesquisa Nacional de Saneamento Básico (PNSB 2000), do IBGE, ou seja, na esfera nacional, apenas $63 \%$ dos 5.507 municípios pesquisados, realizam coleta dos RSS. Com relação à destinação final, cerca de $56 \%$ dos municípios dispõem seus RSS no solo, sendo que $30 \%$ deste total correspondem aos lixões. No que se refere às formas de tratamento, ocorre predomínio da queima a céu aberto (cerca de $20 \%$ ), seguida da incineração $(11 \%)$. As tecnologias de micro-ondas e autoclave para desinfecção dos RSS são adotadas somente por 0,8\% dos municípios. Cerca de $22 \%$ dos municípios não tratam de forma alguma seus RSS ${ }^{(19)}$. Desta forma, o destino final dos RSS não é somente um problema dos governos municipais ou estaduais, mas sim uma preocupação do governo federal.

Em relação à questão 5, que trata da capacitação da equipe envolvida no manejo de RSS, somente no município de Araputanga afirmou-se a preparação de uma das equipes envolvidas no manuseio de RSS, sendo que nos demais municípios a capacitação, ou não existe, ou é desconhecida.

De acordo com os índices, tal resultado é insatisfatório visto que a equipe envolvida nas etapas de manejo deve ser capacitada.

A ANVISA disponibiliza manuais que oferecem aos profissionais informações referentes ao gerenciamento de resíduos, inclusive sobre a implantação do PGRSS. Este promove em seu conteúdo a importância da preparação da equipe envolvida no manejo ${ }^{(19)}$.

Para o sucesso do plano é preciso mobilizar toda organização, objetivando sensibilizar os funcionários quanto ao processo. Deverão ser promovidas reuniões com os vários setores para apresentar a ideia, o possível esquema de trabalho e o que é esperado de cada unidade. Realizar campanhas de sensibilização sobre a temática, além da aplicação de questionários, entre outras atividades que vislumbrem informar e avaliar os resultados obtidos pela equipe ${ }^{(19)}$.

\section{CONCLUSÃO}

Nos municípios de Araputanga, Mirassol do D'oeste e São José dos Quatro Marcos somam-se nove USF e três centros de saúde, local que serve de apoio as demais unidades, distribuindo medicamentos, vacinas, fazendo campanhas, entre outras atividades. Nos dois primeiros municípios citados, nos quais o número de USF é igual ou inferior a três, este centro também é destinado ao atendimento de pacientes. Apesar deste tipo de assistência também ser prestada na unidade central de São José dos Quatro Marcos, observou-se um fluxo menor de pessoas em relação aos demais municípios. Visando completar um total de pelo menos dez entrevistadas, duas enfermeiras atuantes nos centros, sendo uma em Mirassol D'oeste e uma em Araputanga, onde há um maior fluxo de atendimentos, também participaram da coleta dos dados.

Através do estudo realizado foi possível comprovar que nove das dez entrevistadas souberam diagnosticar a situação na qual se encontram os resíduos dentro de sua unidade. Os enfermeiros atuantes nos PSFs devem estar aptos a identificar situações irregulares em seu ambiente de trabalho, solicitar e cobrar melhorias para sua unidade, a fim de aperfeiçoar a assistência, da qual o maior beneficiário é o paciente.

Apontar ou não a existência de irregularidades no gerenciamento é uma atitude vista com cautela por parte das enfermeiras, já que a maioria preferiu manter-se neutra quando questionada a este respeito. Este fato também se explica pelo desconhecimento sobre como são realizadas as etapas. Em apenas um dos municípios, as profissionais que alegaram desconhecer o processo de manejo, optaram por referir falhas no gerenciamento de RSS.

Desta forma conclui-se que o tema "resíduos sólidos" pode ser considerado uma preocupação recente na região estudada. 
Através das respostas obtidas percebeu-se que as enfermeiras avaliadas possuem um conhecimento básico sobre os RSS gerados em seu ambiente de trabalho.

A Enfermagem deve se informar sobre a legislação adotada pela ANVISA referente ao gerenciamento de resíduos, visto que os profissionais da área estão diretamente envolvidos na produção de "lixo" com um potencial poder patogênico. Zelar pela segurança da população deve ser a prioridade para os serviços e buscar as mudanças necessárias a promoção da saúde humana deve fazer parte da rotina de cada profissional.

Com os crescentes prejuízos ambientais provocados pelo acúmulo de resíduos sólidos por parte da população, faz-se necessário a implantação de projetos de conscientização, na tentativa de amenizar as consequências trazidas pela produção excessiva e desnecessária de "lixo", além de informar os cidadãos sobre os perigos de se manusear materiais descartados, devido o risco de contato com parasitas e outros vetores de patologias.

Também se torna de total importância reafirmar a necessidade da capacitação dos recursos humanos envolvidos no gerenciamento de RSS, hábito pouco comum na região dos municípios participantes da pesquisa. Por se tratarem de resíduos potencialmente patogênicos, trazem risco a saúde humana, e a falta de orientação pode contribuir para a ocorrência de acidentes ocupacionais. O uso de Equipamentos de Proteção Individual deve ser um hábito para os profissionais ligados a qualquer etapa do gerenciamento de resíduos.

Como atitude inicial recomenda-se a estabelecer como parte da rotina a busca por conhecimento a respeito, não somente sobre os RSS, mas toda questão ambiental envolvida, como poluição de rios, proliferação de doenças, entre outros prejuízos; conhecer a legislação que regulamenta o manejo dos resíduos sólidos e as diretrizes preconizadas; e ainda, informar-se sobre o PGRSS adotado pelo município. Quando oportuno, o enfermeiro deve propor mudanças e alertar os gestores municipais quanto aos perigos de um gerenciamento mal realizado. Conscientizar a comunidade é uma prática que está ao alcance de todos os profissionais atuantes no PSF, e deve ser realizada a fim de trazer benefícios para a população em geral.

\section{REFERÊNCIAS}

1. Possamai FP, Viana E, Schulz HE, Costa MM, Casagrande E. Lixões inativos na região carbonífera de Santa Catarina: análise dos riscos à saúde pública e ao meio ambiente. Ciênc Saúde Coletiva [periódico na internet]. 2007 Jan [acesso em 16 mar 2010];12(1) Disponível em <http://www. scielo.br/scielo.php?script $=$ sci_arttext $\&$ pid $=$ S1413$-81232007000100020 \&$ lang $=p t>$

2. Lopes MSV, Ximenes LB. Enfermagem e saúde ambiental: possibilidades de atuação para a promoção da saúde. Rev Bras Enferm 2011;64(1):72-7.

3. Philippi JR A, Aguiar AO. Resíduos sólidos: características e gerenciamento. In: Philippi JRA, editor. Saneamento, Saúde e Meio Ambiente: fundamentos para um desenvolvimento sustentável. São Paulo: Manole; 2005. p. 267-321.

4. Siqueira MM, Moraes MS. Saúde coletiva, resíduos sólidos urbanos e os catadores de lixo. Ciênc Saúde Coletiva [periódico na internet]. 2009 Dez [acesso em 17 mar 2010];14(6) Disponível em <http://www. scielo.br/scielo.php?script =sci_arttext\&pid $=$ S1413$-81232009000600018 \&$ lang $=p t>$

5. Chaves LC. Aspectos pessoais, sociais e ambientais envolvidos na manipulação de resíduos sólidos de serviços de saúde pela equipe de enfermagem. Arq Méd ABC [periódico na internet]. 2003 [acesso em 22 Mar 210];28(1): Disponível em < http://www.fmabc.br/ad$\mathrm{min} /$ files/revistas/28amabc010.pdf $>$

6. Takayanagui AMM. Trabalhadores de saúde e meio ambiente: ação educativa do enfermeiro na conscientização para gerenciamento de resíduos sólidos. Ribeirão Preto. Tese [Doutorado em Enfermagem]- Escola de Enfermagem de Ribeirão Preto, Universidade de São Paulo; 1993.

7. Macedo LC, Larocca LM, Chaves MMN, Perna PO, Muntsch SMA, Damaceno EFC, et al. Segregação dos resíduos nos serviços de saúde: a educação ambiental em um hospital-escola. Cogitare Enferm [periódico na internet]. 2007 Abr [acesso em 18 mai 2010 Mai];12(2) Disponível em <http://ojs.c3sl.ufpr.br/ojs2/index.php/cogitare/ article/view/6803/6729>

8. Ministério da Saúde, Agência Nacional de Vigilância Sanitária. RDC No 306/04, de 07 dez 2004. Dispõe sobre o regulamento técnico para o gerenciamento de resíduos de serviços de saúde. [resolução na internet]. Diário Oficial da União 22 dez 2004 [acesso em 10 mar 2010]. Disponível em <http://www.anvisa.gov.br/divulga/noticias/2008/revista_anvisa-060508.pdf >

9. Viana DLP, Pinto JP, Andrade PR, Fernandes MGO. A enfermagem e os resíduos dos serviços de saúde. In: Figueiredo NMA, organizadora. Ensinando a cuidar em saúde pública. São Caetano do Sul: Yendis; 2008. p. 389-400.

10. Horta VA. Teorias de enfermagem. In: Horta VA, com a colaboração de Castellanos BEP. Processo de enfermagem. São Paulo: EPU; 1979. p. 9-27.

11. Ministério da Saúde. Política nacional de promoção da saúde. Brasília: Ministério da Saúde; 2006. p.12.

12. Mielke FB, Olchowsky A. Saúde mental na estratégia saúde da família: avaliação de apoio matricial. Rev Bras Enferm 2010;63(6):900-7.

13. Ministério da Saúde. Política nacional de atenção básica [monografia na internet]. 2006 [acesso em 30 jun 2010] Disponível em <http://portal.saude.gov.br/portal/arquivos/pdf/pactovolume4.pdf $>$

14. Instituto Brasileiro de Geografia e Estatística. Censo 2010 [monografia na internet]. Rio de Janeiro; 2002. [acesso em 10 nov 2010]. Disponível em < http://www.ibge.gov.br/ home/estatistica/populacao/censo2010/MT2010.pdf > 
15. Barros AG, Silva AMP, Júnior LCGC, Rodrigues TM, Santos VEP. Conhecimento de enfermeiras e técnicos acerca do gerenciamento dos resíduos sólidos dos serviços de saúde. An CBCENF [periódico na internet]. [acesso em 20 set 2012] Disponível em < http://189.75.118.67/CBCENF/sistemainscricoes/anais.php? evt $=8 \& \mathrm{sec}=44 \&$ niv $=5.3 \& \bmod =1 \& \operatorname{con}=2996>$

16. Silva NM, Rampelotto EM. Segregação de resíduos sólidos hospitalares. Monografias Ambientais [periódico na internet]. 2012 [acesso em 15 set 2012];5(5) Disponível em < http://cascavel.ufsm.br/revistas/ojs-2.2.2/index.php/ remoa/article/view/4430>

17. Batista NNLAL, Lima SCS, Fernandes RO, Leal SYP,
Carvalho GC, Canuto MAO. Contribuição da enfermagem para a implantação do programa de gerenciamento de resíduos em serviços de saúde (PGRSS) em uma unidade básica: um relato de experiência. In: Anais do $61^{\circ}$ Congresso Brasileiro de Enfermagem [evento na internet]. 2009 dez 07-10; Ceará, Brasil [acesso em 18 set 2012 ]. Disponível em <http://www.abeneventos.com. br/anais_61cben/files/01999.pdf $>$

18. Ministério da Saúde, Agência Nacional de Vigilância Sanitária. Gerenciamento dos Resíduos de Serviços de Saúde. ANVISA [monografia na internet]. 2006 [acesso em 17 ago 2012]. Disponível em <http://bvsms.saude.gov.br/ bvs/publicacoes/manual_gerenciamento_residuos.pdf $>$ 